an ordinary net premium valuation at an appropriately weighted average of the secured yield and the long-term rate of interest are to be obtained. The paper also demonstrates how the $V_{2}$ and $V_{3}$ reserves respond to changes in the assumed long-term rate of interest and secured yield and behave in sometimes unexpected ways.

\title{
THE ANALYSIS, AND AN APPLICATION, OF DIVORCE DATA
}

\author{
BY J. G. SPAIN \\ (Paper No. 33 deposited in the Library in January 1984)
}

A few years ago, it occurred to the author that some form of insurance against the financial hazards associated with divorce might be attractive to those at risk, which is a large proportion of the married population. This may seem fanciful, but there is a real need, particularly since current draft legislation is aimed at attaining the concept of 'a clean break'.

This is the idea behind the paper. While the statistical background has been scrutinized prior to publication (J.I.A., 109, 453), this is not the case for the rest of what has been written, for which the author takes full responsibility.

As will be clear, detailed consideration of the various problems led the author to the inevitable conclusion that such a contract could not be underwritten extensively by a prudent U.K. financial institution, for the reasons stated.

\section{THE MATCHING OF ASSETS TO LIABILITIES}

\author{
BY A. J. WISE
}

(Paper No. 34 deposited in the Library in April 1984)

THE paper, which has been published in full (J.I.A., 111, 375), is supplementary to another by the same author (J.I.A., 111, 445).

It provides the detailed mathematical analysis on which the primary paper is based, and describes the general mathematical model and the alternative definitions of matching which are used. Explicit solutions for matching portfolios are stated with proofs which have been checked by Dr T. Stanley of the City University. Formulae for selected stochastic models are given together with the algorithm which was used to derive all the solutions quoted in the primary paper.

The analysis is given an alterative geometrical treatment and there is also a description of the key features of the actuarial model to which the matching theory relates. 